\title{
Expensive space crystal programme has produced little of scientific value, says panel
}

\section{Washington}

Space experiments in protein crystal growth have yielded no important results to date, says a report released last week by the US National Research Council (NRC).

But the space station's research facilities could be used to assess whether or not crystal growth in zero gravity could ever be worthwhile, says the report.

"At this time, one cannot point to a single case where a space-based crystallization effort was the crucial step in achieving a landmark scientific result," concluded a study panel chaired by Paul Sigler, who before his death in January was a professor of molecular biophysics and biochemistry at Yale University. "In many of the cases that have so far been listed as successful, the improvements obtained have been incremental rather than fundamental."

The report is just the latest criticism of the US space agency NASA's microgravity research programme, which has long touted protein crystal growth as a high-payoff area of research on board the space shuttle and eventually the space station. While the NRC was not so harsh in its judgement as a panel of the American Society for Cell Biology, which two years ago called for scrapping protein crystal growth experiments in space (see Nature 394, 213; 1998), it left little doubt that past NASA claims of important research breakthroughs have been overhyped.

"To date, the impact of microgravity crystallization on structural biology as a whole has been extremely limited," says the NRC report. Sigler's committee found a number of reasons for this. Space-shuttle experiments have been brief and have suffered from the lack of a vibration-free environment. Only a small and insular group has been involved in the research so far. Although many private companies have signed on as partners for space experiments (which NASA press releases often emphasize), "not one has yet committed substantial financial resources".

Another problem is determining exactly what role microgravity has played in past successes. For example, when crystals of the restriction endonuclease EcoRI complexed with DNA (EcoRI-DNA) were grown in orbit, the resulting diffraction data were significantly better than those in similar samples grown on Earth. However, says the NRC panel, it was difficult to attribute the success to microgravity alone when advanced cryogenic techniques and synchrotron radiation analysis were also used.

In fact, the higher data resolutions that are now being achieved using synchrotron

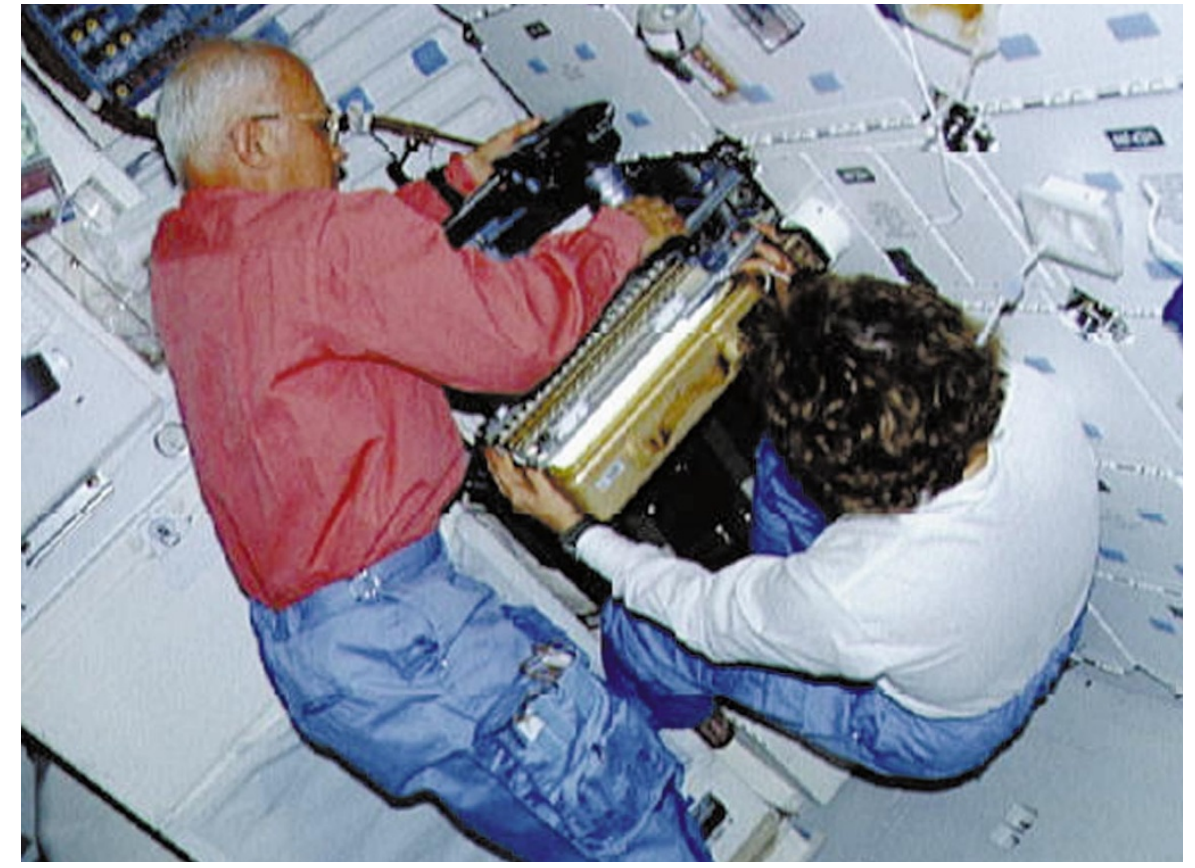

Crystal gazers: predictions about the usefulness of space crystals have not proved true.

sources on the ground have wiped out one of the main advantages offered by space-grown samples - crystal size.

"Although the misconception that size is crucial may persist at NASA, scientists today are interested in crystallization methods that provide higher quality crystals," wrote the panel. And until the value of space-based crystals is proven in the case of specific research problems, the high cost of such research in orbit "is bound to engender resentment in the scientific community".

The NRC panel makes several recommendations. First, the space agency should take action to involve more people in spacebased experiments, as the current recruitment process fails to attract the best scientists and bioengineers. NASA might consider joint solicitations with the National Institutes of Health and the National Science Foundation.

The panel also advises NASA to instigate a high-profile grant programme to settle once and for all the usefulness of spacegrown protein crystals. The space station, with its superior facilities and longer experiment runs, will be a suitable place to conduct such tests, it says.

"If none of the projects produces a spacegrown crystal that enables a breakthrough for the structure determination of a biologically important macromolecular assembly, then NASA should be prepared to terminate its protein crystal growth program," the report concludes.

Tony Reichhardt

\section{Geneticists oppose consent ruling}

\section{Washington}

The chief of the National Human Genome Research Institute has warned against a move to require human geneticists to obtain informed consent from family members, as well as primary subjects, when they solicit people's family histories.

Francis Collins has challenged a recent interpretation of government rules by the Office for Protection from Research Risks (OPRR). It said that when researchers obtain private, identifiable information about individuals - whether primary subjects or their family members - those individuals become by definition human subjects, and their informed consent must therefore be sought for participation.

According to Collins, this "could render a large proportion of current research in human genetics impracticable - with highly detrimental consequences to ultimate public benefit".

The case in question involves a twin study at Virginia Commonwealth 
- University, where the OPRR shut down federally funded research in December, citing numerous deficiencies in human subjects' protection. (The research is now being resumed.)

OPRR's investigation at the university was prompted by a complaint from Richard Curtin, a budget analyst at the US Department of Defense who is the father of college-age twins. One of them received a mailed questionnaire from Linda Corey, a professor of human genetics at the university, that solicited information for the Mid-Atlantic Twin Registry, a 20-year-old registry of 30,000 twin pairs used by medical researchers. The questionnaire asked about the occurrence of hundreds of medical conditions, including abnormal genitalia, alcoholism and infertility, in the twin and family members.

It was "a total invasion" of privacy, says Curtin, who adds that his security clearance at the Department of Defense could be revoked if he suffered from conditions such as mental illness.

"It appears that the [university ethics board] failed to consider the potential social, psychological, and legal risks" presented to twin subjects' family members by the collection of their detailed medical and social information without consent, OPRR wrote to university officials.

But in a letter in January, Collins told OPRR director Gary Ellis that he considered the presumption of risk to family members was unreasonable. "The OPRR's [position] represents a new policy that does not appear to have been informed by broad scientific or public input," he charged, adding that he has "deep concerns" about the decision.

Ellis, in a response to Collins on 22 February, said that OPRR had simply applied existing human subject protection regulations to a particular case, and not implemented a new policy or imposed new general rules.

"Please do not infer any general rulemaking by OPRR regarding informed consent from family members beyond the specifics of this particular research activity," said Ellis.

The American Society of Human Genetics (ASHG) and the National Institute for Child Health and Human Development have both contacted Ellis on the matter.

"We are very concerned about the fact that the collection of family history, which is a very important part of human genetics research, could be inhibited by too much control," says Uta Francke, the previous president of ASHG and a professor of genetics at Stanford University. Meredith Wadman

\section{Panel will seek 'appropriate' AIDS goals for South Africa}

\section{Cape Town}

South Africa's health department is setting up a panel of experts to tackle the AIDS epidemic, health minister Manto TshabalalaMsimang confirmed this week.

The panel of some 30 local and international experts will "explore all aspects of... developing prevention and treatment strategies that are appropriate to the African reality," she says in a press release.

The minister is hoping to reassure AIDS activists, who have accused the government of wilfully mismanaging the epidemic in South Africa, that the panel will be free to work to its own conclusions.

But she has not confirmed or denied the rumour that controversial biochemist Peter Duesberg of the University of California at Berkeley - who claims that the HIV virus is not the cause of AIDS - may be on the panel.

"Those with more extreme views are unlikely to participate because we are looking for a consensus," she says. AIDS activists continue to suspect that the government line supports the Duesberg claim.

The panel will review the general prevention and treatment (as well as the causes and diagnosis) of HIV/AIDS and opportunistic infections. It will also review the prevention of infection following rape or needle-stick injuries, and from mother to child.

The South African government recently refused to supply anti-retroviral drugs such as AZT to pregnant women within the state health system. It apparently believes that the

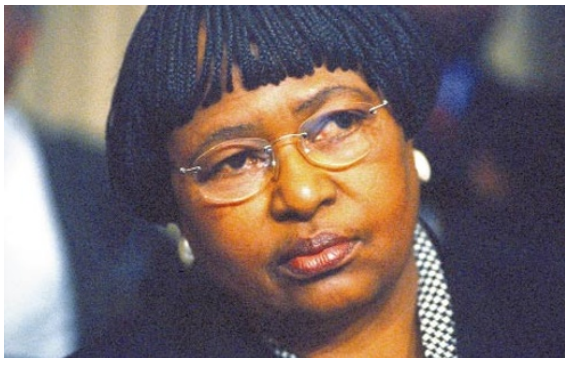

Tshabalala-Msimang: 'no hidden agendas'.

risks of using the drugs outweigh the benefits, despite advice to the contrary from different expert groups (see Nature 403, 692; 2000). Tshabalala-Msimang says this decision could be reconsidered if the panel convincingly shows that treatment would be effective. But an "ingenious solution" to the difficulties of financing the treatment would need to be found in such a case, she says.

Tshabalala-Msimang denies claims by the Treatment Action Campaign (TAC) that the panel is "a justification for the immoral, unscientific and unlawful decision" not to give the drugs to pregnant women. "I hope the work of the panel will demonstrate that we have no hidden agendas," she says.

The TAC has challenged the minister and her advisers to publish evidence from any scientific study to prove that provision of AZT is not economically feasible in South Africa, or that AZT is toxic to mother or child when given to women in the last trimester of pregnancy. Michael Cherry

\section{\$350m gift boosts MIT brain power}

\section{Boston}

The Massachusetts Institute of Technology has a bold plan to make itself a world leader in neuroscience. Last week, MIT announced the creation of an ambitious institute to study the human brain.

It will be the centrepiece of a new neuroscience complex, scheduled for completion in 2004. The McGovern Institute for Brain Research will be joined in the complex by an expanded version of MIT's Center for Learning and Memory (CLM) and a $\$ 20$ million centre for brain imaging. "With all the resources here, MIT should stand among the best in this field," says MIT molecular biologist Phillip Sharp, who will direct the institute.

Patrick McGovern, founder of computer publishing giant the International Data Group, and his wife Lore Harp McGovern, a high-tech entrepreneur, will give $\mathbf{\$ 3 5 0}$ million over 20 years - the largest gift ever pledged to a US university. They picked MIT, from which Patrick McGovern graduated in 1959 , because of its reputation for fostering interdisciplinary research.

The McGovern Institute will house 16 labs and 300 staff. Its model is theWhitehead Institute for Biomedical Research, also at MIT, where Lore Harp McGovern chairs the Board of Associates and her husband is a trustee. "I was impressed with how much progress they've made, for example, in understanding the causes of cancer and other diseases," says Patrick McGovern. "It shows what can be done at a missionoriented centre if you bring the right people together."

For Sharp, who won the Nobel prize in medicine in 1993 for his work on RNA 